AURELIA JOURNAL VOL. 3 (1) OKTOBER 2021 : 59-71

Aurelia Journal

(Authentic Research of Global Fisheries Application Journal)

E-ISSN 2715-7113

e-mail: aurelia.journal@gmail.com

\title{
STUDI PENGOPERASIAN PURSE SEINE DI KM. SUMBER ABADI
}

\section{OPERATION STUDY OF PURSE SEINE IN KM. SUMBER ABADI}

\author{
Roma Yuli F Hutapea ${ }^{*}$, Ifan Nur Alwi², Ratu Sari Mardiah ${ }^{1}$, Ratih Purnama Sari', \\ Suci Asrina Ikhsan ${ }^{1}$ \\ 1 Dosen Program Studi Perikanan Tangkap, Politeknik Kelautan dan Perikanan Dumai, Indonesia \\ 2 Mahasiswa Program Studi Perikanan Tangkap, Politeknik Kelautan dan Perikanan Dumai, Indonesia \\ * Korespodensi: romafelina@yahoo.co.id (RYF Hutapea) \\ Diterima 15 Agustus 2021 - Disetujui 22 September 2021
}

\begin{abstract}
ABSTRAK. Perairan Selat Malaka yang subur memiliki bermacam-macam sumber daya ikan laut diantaranya jenis-jenis udang, ikan demersal dan ikan pelagis. Sumber daya ikan di WPP 571 yang kaya akan ikan pelagis, membuat alat tangkap purse seine cocok untuk dioperasikan sekitar perairan WPP 571. Purse seine merupakan salah satu jenis alat tangkap aktif yang bersifat multi spesies, karena hasil tangkapannya lebih dari satu jenis ikan. Tujuan penelitian ini penulis ingin memahami alat bantu penangkapan purse seine dan alat navigasi di KM. Sumber Abadi dan pengoperasian di KM. Sumber Abadi. Hasil dari data yang didapat dilapangan diketahui daerah penangkapan ikan KM.Sumber Abadi di WPP 571 Selat Malaka. Pengoperasian alat tangkap purse seinesecara bertahap, yaitu penurunan alat tangkap (setting) penarikan tali kerutpenarikan badan jaring (hauling) penaikan hasil tangkapan (brailing), waktu yang diperlukan untuk satu kali pengoperasian adalah 2 sampai 3 jam. Alat bantu penangkapan purse seine yang ada di atas kapal KM. Sumber Abadi adalah Lampu robot, Gardan, Power block, GPS (Global Position System), Echsouder dan Radio SSB.
\end{abstract}

KATA KUNCI: Alat bantu penangkapan, alat navigasi; pengoperasian, pukat cincin

ABSTRACT. The fertile waters of the Malacca Strait have a variety of marine fish resources including types of shrimp, demersal fish and pelagic fish. Fish resources in FMA 571 are rich in pelagic fish, making purse seine fishing gear suitable for operation around the waters of FMA 571. Purse seine is one type of active fishing gear that is multi-species, because it catches more than one type of fish. The purpose of this study the author wants to understand the purse seine fishing tools and navigation tools in KM. Sumber Abadi and operation in KM. Eternal Source. The results of the data obtained in the field are known to the fishing area of KM. Sumber Abadi in WPP 571 Malacca Strait. The operation of purse seine fishing gear is gradual, i.e. decreasing the fishing gear (setting), pulling the rope, pulling the net (Hauling) and increasing the catch (brailing), the time required for one operation is 2 to 3 hours. Purse seine fishing aids on board the KM. Sumber Abadi are Robot lights, Axle, Power block, GPS (Global Position System), Echsouder and SSB Radio.

KEYWORDS: Fishing aids, navigational devices, operation, purse seine

\section{Pendahuluan}

Perairan Selat Malaka yang subur memiliki bermacam-macam sumber daya ikan laut diantaranya jenisjenis udang, ikan demersal dan ikan pelagis. Damanik, Lubis, \& Astuti (2016) menyatakan bahwa Wilayah Pengelolaan Perikanan (WPP) 571 Selat Malaka ini unik karena secara yuridis, perairan ini berada dibawah dua negara, yaitu Indonesia dan Malaysia sehingga dalam pengelolaan perikanan ini menjadi tanggung jawab bersama (terutama untuk stok ikan yang bersifat stradling and shared). Fishing ground yang berada di WPP 571 Selat Malaka memiliki potensi ikan pelagis yang sangat banyak dan merupakan wilayah yang memiliki sumber daya ikan pelagis kecil yang cukup tinggi. 
Potensi ikan di WPP 571 Selat Malaka meliputi 9 kelompok ikan dan didominasi ikan karang sekitar $25 \%$. Komposisi jenis ikan pelagis kecil (termasuk cumi-cumi) didapatkan lebih dari 12 jenis dengan dominasi ikan layang deles (Decapterus macrosoma) sekitar 42\%, sementara untuk ikan pelagis besar didapatkan lebih dari 10 jenis dan yang mendominasi ikan tenggiri (Euthynnus affinis) sekitar $39 \%$ dan ikan demersal didapatkan 39 famili dengan ikan yang mendominasi famili Scianidae (Johniu ssp) sekitar 23\% (Baihaqi \& Hufiadi, 2015). Sumber daya ikan di WPP 571 yang kaya akan ikan pelagis, membuat alat tangkap purse seine cocok untuk dioperasikan sekitar perairan WPP 571.

Purse seine merupakan salah satu jenis alat tangkap aktif yang bersifat multi spesies, karena hasil tangkapannya lebih dari satu jenis ikan. Alat tangkap purse seine sangat efektif untuk menangkap ikan pelagis kecil yang bergerombol dengan kepadatan yang tinggi (Kefi, Katiandagho, \& Paransa, 2013). Banyaknya ikan pelagis yang terdapat di WPP 571 membuat alat tangkap purse seine akan lebih dominan digunakan. Karakteristik purse seine adalah mengurung gerombolan ikan. Saat ini purse seine adalah salah satu alat tangkap paling efektif untuk menangkap ikan bergerombol.

Fokus penelitian ini adalah pada pengoperasian purse seine di KM. Sumber Abadi dan alat bantu yang digunakan di KM. Sumber Abadi. Beberapa penelitian yang berkaitan dengan topik penelitian penulis adalah penelitian Steven, T. (2017) membahas tentang komposisi hasil tangkapan di WPP 571 yang menyatakan bahwa komposisi ikan hasil tangkapan di WPP 571 yaitu ikan layang, ikan tongkol, ikan kembung, ikan selar, ikan teri, ikan tembang dan ikan layur.

Kedua adalah Hariati, Taufik, \& Zamroni (2003) membahas tentang hasil tangkapan di Selat Malaka yang menyatakan bahwa hasil tangkapan didominasi oleh ikan layang (Decapterus spp). Ketiga adalah Suman, A. et al. (2018) membahas tentang status stok SDI tahun 2016 di WPP NRI yang menyatakan bahwa hasil analisis menunjukkan potensi sumber daya ikan di perairan Indonesia (WPP $\mathrm{NRI}$ ) adalah sebesar 12,54 juta ton per tahun dengan potensi tertinggi sebagai ikan pelagis kecil sebesar 4,88 juta ton/tahun (39\%) dan yang terendah adalah lobster sebesar 11.159 ton (1\%) Berdasarkan WPP NRI, potensi SDI ikan tertinggi sebesar 2,64 juta ton (21\%) terdapat di WPP NRI 718 (Laut Aru dan Laut Arafura) dan yang terendah sebesar 425.444 ton di perairan WPP NRI 571 (Selat Malaka dan Laut Andaman). Topik penelitian yang pernah ada hanya membahas komposisi hasil tangkapan, sedangkan pada topik penelitian ini penulis membahas alat bantu penangkapan purse seine dan alat navigasi di KM. Sumber Abadi dan pengoperasian di KM. Sumber Abadi. Tujuan dari penelitian yg dilakukan di KM. Sumber Abadi adalah memahami alat bantu penangkapan purse seine dan alat navigasi yang digunakan di KM. Sumber Abadi. Tujuan berikutnya adalah memahami pengoperasian alat tangkap purse seine di KM. Sumber Abadi.

\section{Bahan dan Metode}

\subsection{Waktu dan Lokasi Penelitian}

Penelitian ini dilaksanakan pada bulan Maret hingga Juni 2021, objek yang dikaji dalam penelitian Wilayah Pengelolaan Perikanan (WPP) 571 Selat Malaka Provinsi Sumatera Utara. Peta WPP 571 Selat Malaka disajikan pada Gambar 1.

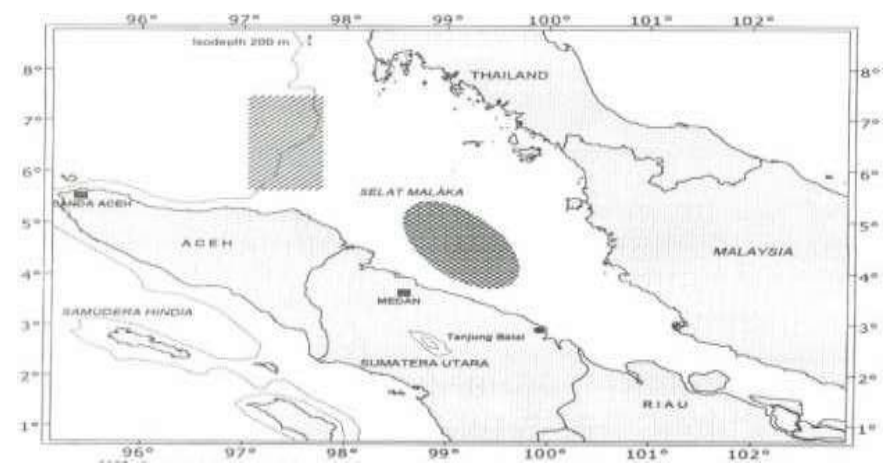

(Sumber: Hariati T et al 2003)

Gambar 1. WPP 571 Selat Malaka Provinsi Sumatera Utara. 


\subsection{Alat dan Bahan}

Alat dan bahan yang digunakan pada saat penelitian disajikan pada Tabel 1.

Tabel 1. Alat dan Bahan.

\begin{tabular}{ll}
\hline Alat dan Bahan & Kegunaan \\
\hline $\begin{array}{l}\text { Alat tulis } \\
\text { Handphone }\end{array}$ & Mencatat data \\
Kapal & $\begin{array}{l}\text { Dokumentasi } \\
\text { Tansportasi nelayan yang digunakan nelayan } \\
\text { menuju fishing ground }\end{array}$ \\
$\begin{array}{ll}\text { Alat tangkap Purse seine } & \text { Digunakan untuk menangkap ikan } \\
\text { Alat Bantu Penangkapan Ikan Katrol, lampu robot } \\
\text { (galaxy), gardan, power block }\end{array}$ & Memudahkan proses penangkapan ikan \\
$\begin{array}{l}\text { Generator } \\
\text { Alat Navigasi (GPS, Echosounder, } \\
\text { Radio SSB) }\end{array}$ & Sebagai mesin pembangkit listrik \\
Satu set alat keselamatan & Digunakan untuk menentukan posisi kapal \\
\hline
\end{tabular}

\subsection{Metode Pengambilan Data dan Analisis Data}

Metode pengumpulan data yang digunakan adalah observasi dan wawancara. Pengumpulan data dilakukan selama 4 bulan dengan 3 kali trip melaut pada kapal purse seine PPS Belawan yang beroperasi di WPP 571 Selat Malaka. Penulis mengamati, melakukan kegiatan pengoperasian alat tangkap purse seine serta melakukan melakukan wawancara kepada nahkoda dan nelayan di KM Sumber Abadi. Penulis melakukan kegiatan pengoperasian alat tangkap selama 3 trip penangkapan.

Analisis data yang digunakan adalah analisis data deskriptif, pada satu unit kapal purse seine yang beroperasi di WPP 571 Selat Malaka. Linarwati, Fathon, \& Minarwasih (2016) menyatakan bahwa penelitian deskriptif merupakan penelitian yang berusaha mendeskripsikan dan menginterpretasikan sesuatu, misalnya kondisi atau hubungan yang ada, pendapat yang berkembang, proses yang sedang berlangsung, akibat atau efek yang terjadi, atau tentang kecenderungan yang sedang berlangsung. Untuk membuat deskriptif, gambaran atau lukisan secara sistematis, faktual dan akurat mengenai faktafakta, sifat-sifat serta hubunganantar fenomenal yang diselidiki. Setelah hasil tangkapan didapat kemudian data hasil tangkapan tersebut diubah kedalam tabulatif. Data teknis yang dilakukan dengan cara mengikuti secara langsung kegiatan operasi penangkapan ikan untuk mengetahui data yang berhubungan dengan teknik operasi penangkapan ikan yangditerapkan nelayan purse seine.

\section{Hasil dan Pembahasan}

\subsection{Data Kapal}

Kapal purse seine adalah suatu armada yang digunakan nelayan untuk melakukan penangkapan ikan pelagis. Surur (2010) menyatakan kapal purse seine mempunyai persyaratan khusus, diantaranya harus memiliki dek yang luas, stabil dan mudah diolah gerak, yang harus mempunyai konstruksi yang baik dimana kapal harus kuat, lebar dan memiliki kelajuan yang baik dalam melingkari gerombolan ikan. Kapal yang digunakan pada penelitian yaitu KM. Sumber Abadiyang bersandar di PPS Belawan.

KM. Sumber Abadi adalah tipe kapal penangkap ikan (PS) berukuran 59 GTdengan material kayu yang mempunyai 6 buah palka ikan, 1 buah robot (power block) dan dibuat pada tahun 1995. KM Sumber Abadi menggunakan mesin dieselmerk Nissan dengan daya HP 240 PK sebagai penggerak utama kapal. Dengan memiliki daya mesin sebesar 240 PK KM. Sumber Abadi memiliki kecepatanyang cukup baik dalam berolah gerak dan melakukan pelingkaran alat tangkap purse seine pada saat pengoperasian. Dengan kekuatan mesin yang lebih besar, maka proses pelingkaran gerombolan ikan juga lebih cepat 
sehingga kemungkinan ikan untuk lolos juga semakin kecil. Gambar layout dan spesifikasi KM. Sumber Abadi disajikan pada Gambar 2 dan Tabel 2.

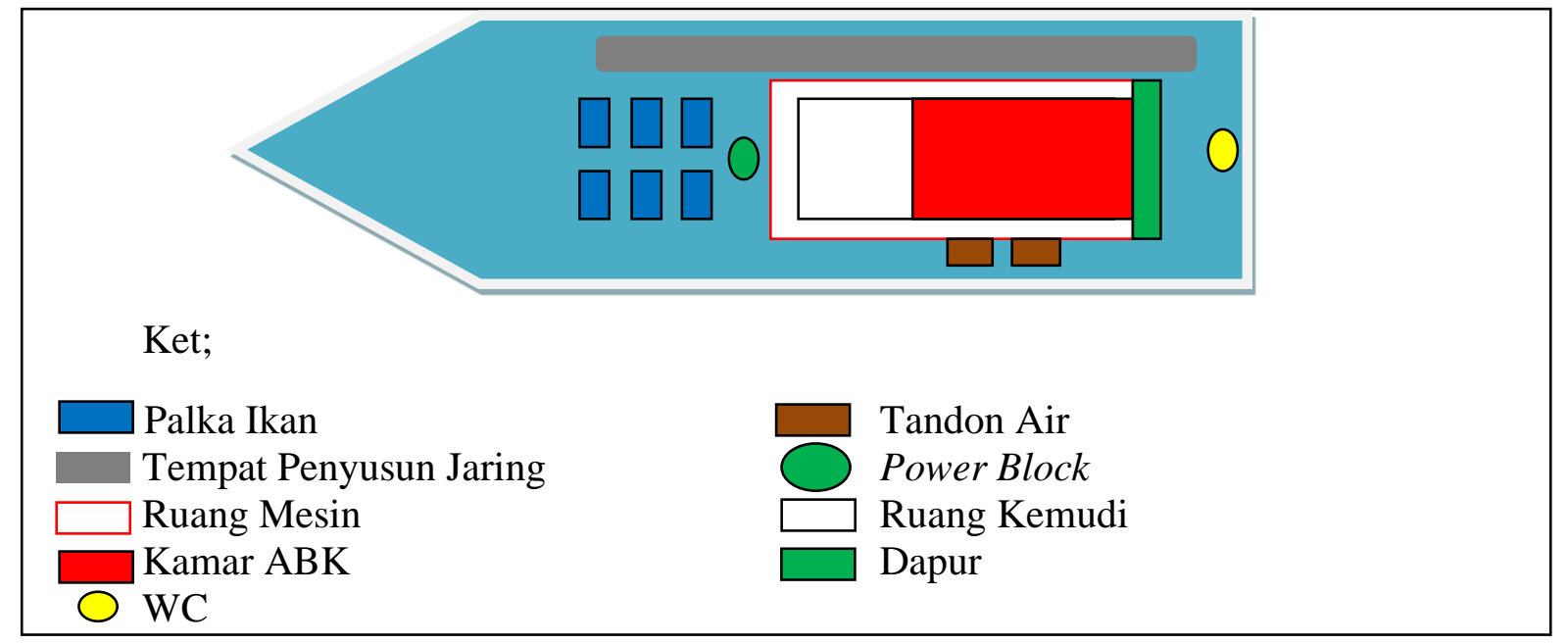

Gambar 2. Layout KM. Sumber Abadi.

Tabel 2. Spesifikasi KM. Sumber Abadi.

\begin{tabular}{cll} 
No & \multicolumn{1}{c}{ Uraian } & \multicolumn{1}{c}{ Spesifikasi } \\
\hline 1 & Nama Kapal & KM. Sumber Abadi \\
2 & Call Sign & A/571/KP-PS/001897 \\
3 & Tanda Selar & BELAWAN/GT.59 No. 538/Ppa \\
4 & Tipe Kapal & Penangkap Ikan (PS) \\
5 & Material Kapal & Kayu Fibber \\
6 & Tahun Pembuatan & 1995 \\
7 & Tempat Pembuatan & Belawan \\
8 & LOA & $25.50 \mathrm{~m}$ \\
9 & Lebar Kapal & $6.30 \mathrm{~m}$ \\
10 & Draf Kapal & $3.10 \mathrm{~m}$ \\
11 & Bobot Kotor & $59 \mathrm{GT}$ \\
12 & Bobot Bersih & $35 \mathrm{GT}$ \\
\hline
\end{tabular}

\subsection{Alat dan Mesin Bantu Penangkapan Ikan}

Alat dan mesin bantu penangkapan ikan digunakan untuk mempermudahkan pekerjaan nelayan agar proses kegiatan penangkapan ikan dapat berjalan dengan efektif dan efisien. Penggunaan alat bantu dan mesin bantu dalam proses penangkapan ikan untuk mempermudah dalam proses pengoperasian alat penangkapan ikan dan menghemat waktu dalam pencarian fishing ground yang sesuai. Alat dan mesin bantu penangkapan ikan yang digunakan oleh KM. Sumber Abadi adalah sebagai berikut:

\section{a) Lampu robot}

Lampu robot yang digunakan oleh KM. Sumber Abadi bertujuan untuk menarik perhatian ikan yang memiliki sifat tertarik pada cahaya sehingga ikan berkumpul disekitar kapal. Pratama, Hapsari \& Triarso (2016) lampu pada alat tangkap pukat cincin yaitu untuk memikat daya tarik ikan untuk berkumpul di sekitar kapal. Tetapi masing-masing ikan mempunyai respon terhadap besarnya intensitas cahaya yang berbeda-beda.

Buwono, Manullang, \& Eneste (2020) menyatakan bahwa penggunaan daya listrik terbesar untuk kapal ikan adalah kebutuhan lampu set dan lampu robot dengan kebutuhan daya 1200 dan 1000 yang 
dipergunakan untuk menarik perhatian ikan agar mendekati kapal, jumlah penggunaannya juga yang paling banyak yaitu 12-20 buah. KM. Sumber Abadi memiliki 15 buah lampu robot. Gambar lampu robot/galaxi disajikan pada Gambar 3.

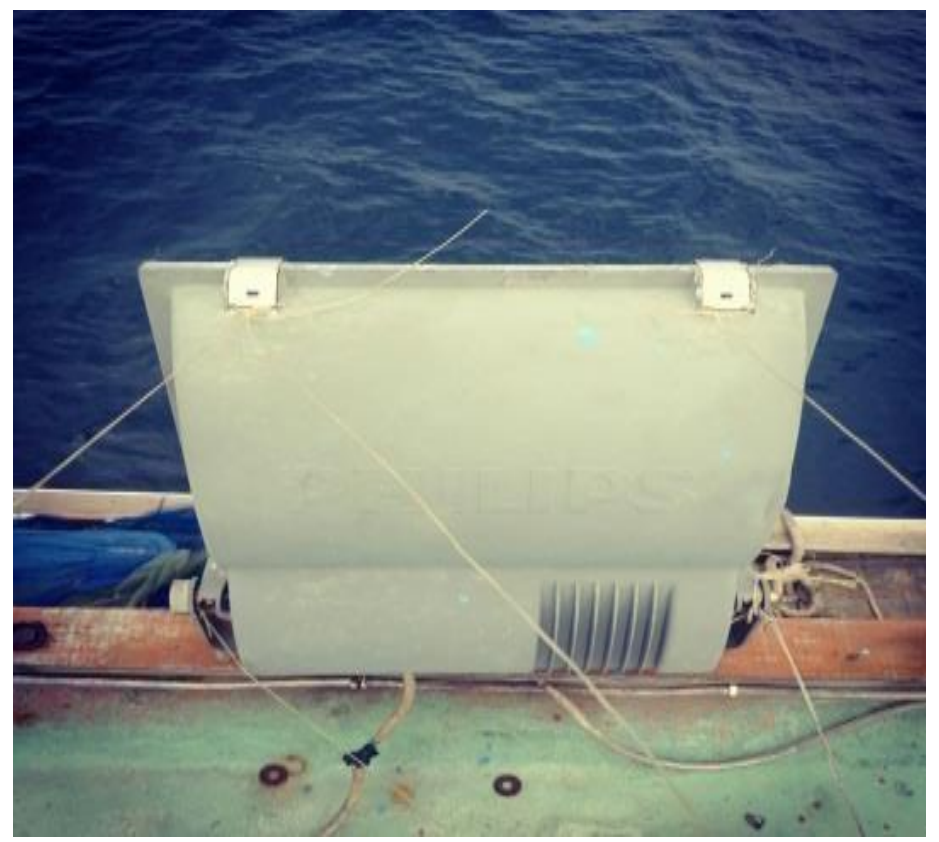

Gambar 3. Lampu Robot/Galaxi KM. Sumber Abadi.

\section{b) Gardan}

Gardan berfungsi sebagai alat untuk menarik tali kerut dan benda-benda berat lainnya seperti palung, caduk dan jangkar. Caranya dengan melingkari tali yang akan ditarik sebanyak 2-3 kali pada gardan yang dalam hidup/berputar. Gardan ini ditempatkan pada sisi kiri dan kanan anjungan kapal.

Gardan yang digunakan pada KM. Sumber Abadi terbuat dari bahan besi kuningan, gardan digerakan dengan menggunakan tenaga mesin utama yang diatur dengan kontrol pembagi. Kecepatan putaran gardan dapat diatur sesuai kebutuhan dengan alat pengendali (kopling) yang dioperasikan dari kamar mesin. Gambar gardan disajikan pada Gambar 4.

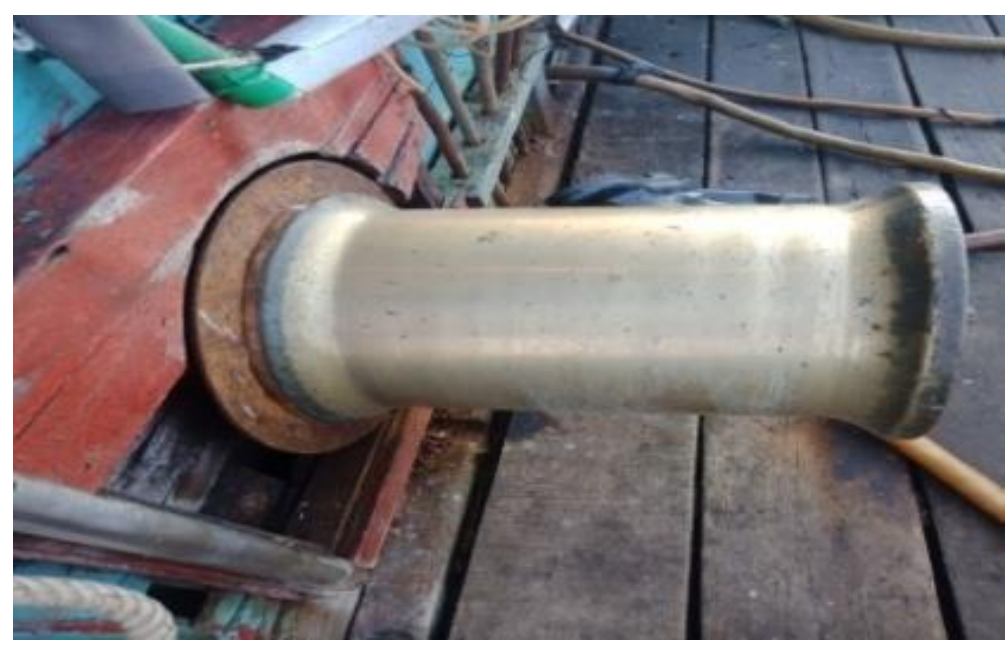

Gambar 4. Gardan KM. Sumber Abadi.

\section{c) Power block}

Power Block adalah mesin bantu yang digunakan untuk menarik jaring purse seine dari dalam air ke atas deck kapal purse seine (Pakmet, 2017). Robot/power block sangat membantu dan mempercepat pekerjaan nelayan dalam proses pengangkatan (hauling) padaalat tangkap purse seine. Power block 
yang ada di KM. Sumber Abadi merk TALANO bertenaga hidrolik serta memiliki daya gerak yang besar. Gambar power block disajikan pada Gambar 5.

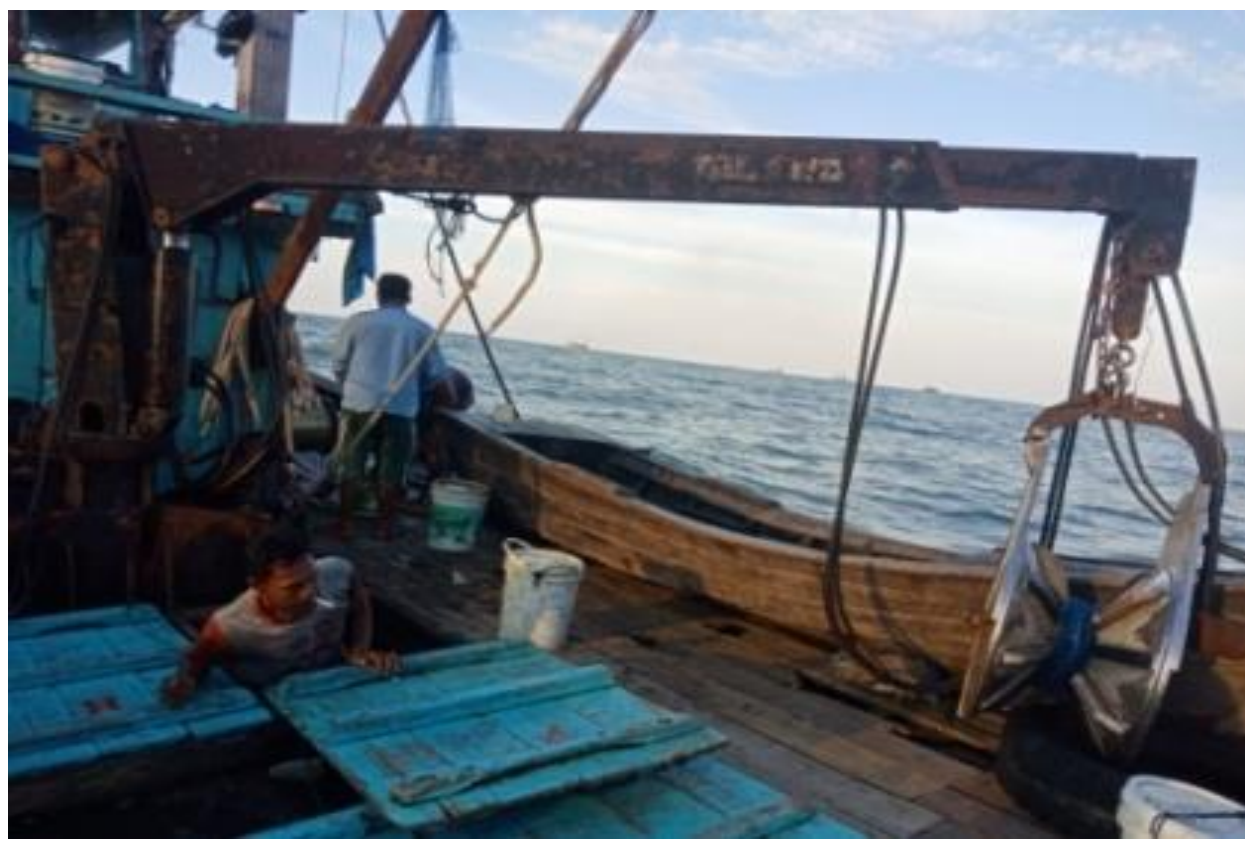

Gambar 5. Power Block KM. Sumber Abadi.

\subsection{Alat Navigasi}

Keberhasilan suatu operasi penangkapan ikan sangat mempengaruhi sarana penunjang seperti alat navigasi dan komunikasi, alat navigasi yang ada di KM. Sumber Abadi adalah sebagai berikut:

\section{a) GPS (Global Position System)}

Fungsi pokok GPS adalah untuk menentukan posisi lintang dan bujur kapal, kecepatan kapal, jarak tempuh kapal, memperkirakan jarak waktu datang di pelabuhan tujuan, sisa waktu tempuh, menyimpan posisi kapal yang diinginkan, menentukan jejak pelayaran dalam bentuk peta. Nakhoda KM. Sumber Abadi menggunakan GPS sebagai alat untuk mencatat/menyimpan titik kordinat tuasan/rumpon dan daerah penangkapan ikan (fishing ground). GPS yang digunakan oleh KM. Sumber Abadi ialah GPS 128 GARMIN. Gambar GPS disajikan pada Gambar 6.

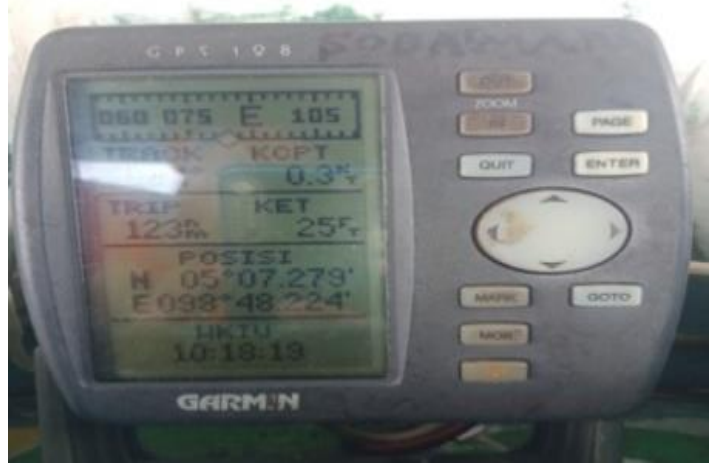

\section{Gambar 6. GPS (Global Position System) KM. Sumber Abadi.}

\section{b) Echsouder}

Echsouder adalah alat navigasi yang digunakan untuk mengetahui kedalaman perairan dan mendeteksi adanya gerombolan ikan di dalam air. Menurut Pakmet (2017) menyatakan bahwa echosounder adalah alat elektronik yang dapat menghasilkan citra gambar dan data tentang objek-objek di dalam air seperti: 
keberadaan ikan, posisi, arah renang, densitas, ukuran, suhu air, kedalaman perairan dan jenis dasar perairan. Echsouder yang digunakan oleh KM. Sumber Abadi ialah ONWA KP-667 MK II. Gambar Echsouderdisajikan pada Gambar 7.

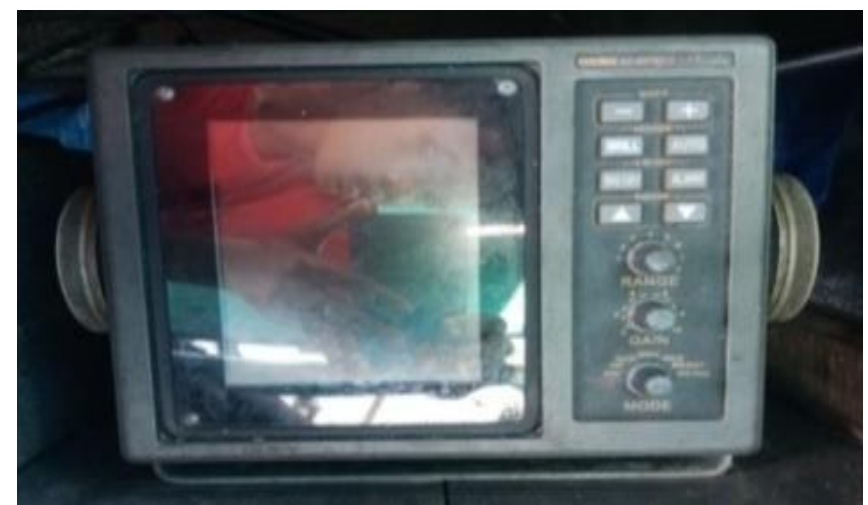

Gambar 7. Echsouder KM. Sumber Abadi.

\section{c) Radio SSB}

Radio adalah sebagai alat yang digunakan untuk berkomunikasi antara awak kapal yang satu dengan awak kapal yang lainnya dan berkomunikasi dari kapal ke pelabuhan. Nakhoda KM. Sumber Abadi menggunakan radio SSB untuk mencari informasi tentang daerah penangkapan ikan dari kapal penangkap ikan lainya. KM. Sumber Abadi menggunakan radio merk ICOM IC; Type 725. Gambar radio SSB disajikan pada Gambar 8.

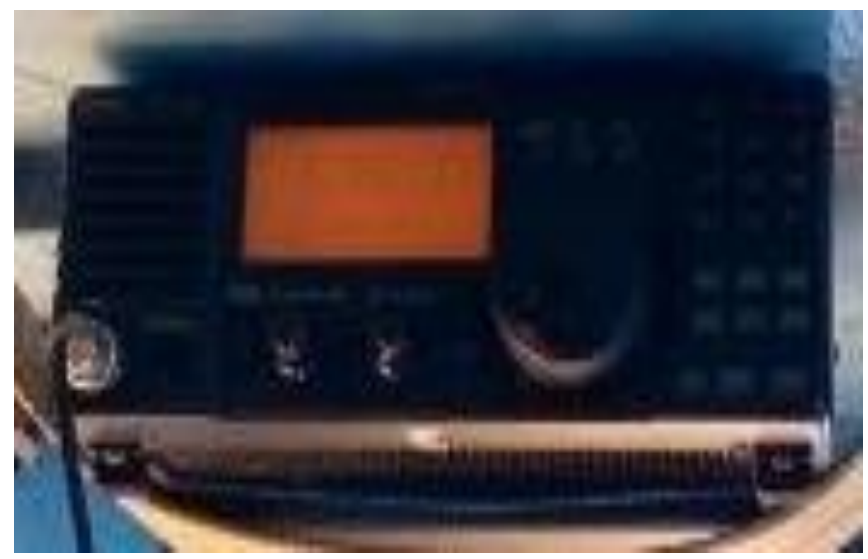

Gambar 8. Radio SSB KM. Sumber Abadi.

\subsection{Konstruksi Alat Tangkap}

Berdasarkan hasil yang didapatkan di lapangan bahwa konstruksi alat tangkap purse seine yang terdapat di KM. Sumber Abadi memiliki dua komponen, dan bahan yang digunakan pun sesuai dengan pernyataan Silitonga, Isnaiah, \& Syofyan (2016) yaitu komponen utama yang merupakan jaring (webbing) yang terdiri dari kantong jaring, bahu jaring, perut jaring dan sayap jaring. Komponen kedua adalah komponen penunjang yang terdiri dari srampatan (selvedge), tali ris atas (upper ris line), tali ris bawah (under ris line), tali pelampung (float line), tali pemberat (sinker line), tali cincin (ring line), tali kerut (purse line), pelampung (float), pemberat (sinker), dan cincin (ring).Berikut konstruksi dari alat tangkap purse seine KM. Sumber Abadi disajikan pada Tabel 3. 
Tabel 3. Konstruksi Dari Alat Tangkap Purse Seine KM. Sumber Abadi.

\begin{tabular}{ll}
\multicolumn{1}{c}{ Uraian } & \multicolumn{1}{c}{ Spesifikasi } \\
\hline Bahan bagian badan jaring & Polyethylene(PE) $\varnothing 0,6 \& 0,9 \mathrm{~mm}$ \\
Bahan bagian sayap & Polyethylene(PE) $\varnothing 0,6 \& 0,9 \mathrm{~mm}$ \\
Bahan bagian kantung & Polyethylene(PE) $\varnothing 0,30 \mathrm{~mm}$ \\
Ukuran mata jaring & 2 inchi/ $24 \mathrm{~mm}$ \\
Panjang alat tangkap & $400 \mathrm{~m}$ \\
Dalam alat tangkap & $60 \mathrm{~m}$ \\
Tali ris atas dan tali pelampung & Polyethilene (PE) $\varnothing 16 \mathrm{~mm} .420 \mathrm{~m}$ \\
Tali ris bawah dan tali pemberat & Polyethilene (PE) $\varnothing 16 \mathrm{~mm} .420 \mathrm{~m}$ \\
Bahan pelampung & Polivynil cloride (PVC) 1000 buah \\
Bahan pemberat & Timah (pb) 1500 buah \\
Cincin & Besi putih 105 buah \\
Jarak antar cincin & $3000 \mathrm{~cm}$ \\
\hline
\end{tabular}

\section{a) Bagian badan jaring (Webbing)}

KM. Sumber Abadi menggunakan jaring berbahan Polyethilene (PE) dengan mesh size2 inchi dengan ukuran diameter benang $0,6 \mathrm{~mm}$. Konstruksi pada purse seine memiliki 3 bagian yaitu, bagian badan jaring dengan mesh size 2 inchi, bagian sayap jaring dengan mesh size 2 inchi dan bagian kantung dengan mesh size 1 inchi dan memiliki diameter benang paling besar.

i. Tali ris atas dan tali ris bawah

Tali ris atas dan tali ris bawah yang digunakan oleh KM. Sumber Abadi berbahan Polyethylene (PE) dengan ukuran diameter tali $16 \mathrm{~mm}$ dan panjang tali $420 \mathrm{~m}$ dengan arah pintalan $\mathrm{Z}$ (pintalan kiri).

ii. Pelampung

Pelampung yang digunakan oleh KM. Sumber Abadi pada alat tangkap purse seine terbuat dari bahan Polivynil cloride (PVC) yang berjumlah 1000 buah dengan panjang $170 \mathrm{~mm}$ dan jarak antar setiap pelampung adalah $50 \mathrm{~cm}$.

iii. Cincin

Cincin yang digunakan pada alat tangkap purse seine KM. Sumber Abadi terbuat dari besi putih dengan ukuran ketebalan $16 \mathrm{~mm}$ yang berjumlah 105 buah dan jarang antar setiap cincin adalah $3 \mathrm{~m}$.

iv. Pemberat

Pemberat yang digunakan oleh KM Sumber Abadi berbahan timah hitam/ploombom (pb) memiliki panjang $55 \mathrm{~mm}$, diameter luar $30 \mathrm{~mm}$, berjumlah 1500 buah dan jarak antar setiap pemberat adalah $30 \mathrm{~cm}$.

\subsection{Daerah Penangkapan Ikan}

Penentuan daerah penangkapan ikan dilakukan sejak kapal berangkat kelaut, lokasi penangkapan berdasarkan pengalaman Nakhoda dan informasi dari kapal yang baru melaut serta kapal yang masih di laut dengan bantuan radio SSB. KM. Sumber Abadi memliki rumpon disekitar wilayah Selat Malaka yang sudah lama terpasang.

Daerah penangkapan ikan KM. Sumber Abadi ialah di WPP 571 perairan Selat Malaka, waktu tempuh perjalanan KM. Sumber Abadi menuju fishing ground adalah 10 sampai 15 jam. Rumpon yang di pasang KM. Sumber Abadi berjarak \pm 40 hingga 60 mil laut dari fishing base. 


\subsection{Pengoperasian Purse Seine}

Sebelum melakukan kegiatan penangkapan ikan, terlebih dahulu dilakukan persiapan kapal, diantaranya adalah menyiapkan dokumen kapal seperti SIUP, SIPI, SKK 60 mil (Nakhoda dan KKM), pas ukur dalam negeri, surat persetujuan berlayar (SPB), BBM, es, air tawar dan bahan logistik. Jumlah bahan-bahan logistik tergantung dari lamanya waktu operasi jumlah ABK dan besarnya ukuran kapal.

Kemudian nakhoda mencari daerah penangkapan yang diperkirakan banyak terdapat ikan termasuk memeriksa rumpon-rumpon yang ditaruh permanen, setelah mendapatkan lokasi penangkapan disekitar rumpon, kapal akan berlabuh jangkar disekitar rumpon untuk menunggu malam, menjelang sore hari, lampu-lampu robot dinyalakan untuk menarik perhatian disekitar rumpon, dan setting akan dilakukan pada pukul 22.00 WIB sampai dini hari menjelang matahari terbit. Terdapat 2 jenis metode operasi penangkapan yang dilakukan KM. Sumber Abadi yaitu:

a) Mengejar gerombolan ikan

Metode operasi penangkapan dengan mengejar gerombolan ikan yang dilakukan pada pagi atau sore hari dimana ikan sedang aktif mencari makanan di permukaan perairan. Metode ini jarang dilakukan karena gerombolan ikan yang naik kepermukaan perairan jarang sekali dijumpai.

b) Mengumpulkan ikan

Metode mengumpulkan ikan yang dilakukan dengan menggunakan alat bantu penangkapan ikan yang berfungsi untuk menarik perhatian ikan sehingga ikan berkumpul di sekitar kapal. Pengoperasian alat tangkap dengan metode ini dilakukan pada malam hari dan dini hari sebelum matahari terbit sehingga efektifitas lampu dapat maksimal.

Walaupun terdapat dua jenis metode operasi penangkapan dengan purse seine, namun secara garis besar keduanya memiliki prosedur setting yang sama, perbedaannya adalah pada metode pengumpulan ikan dilakukan pemikat ikan dengan menggunakan rumpon dan cahaya sedangkan pada metode pengejaran gerombolan ikan tidak dilakukan.

Pengoperasian purse seine di KM. Sumber Abadi sesuai dengan Adi, Bambang, Asriyanto (2014) yang menyatakan ada beberapa tahap dalam kegiatan pengoperasian alat tangkap ikan seperti menemukan kawanan ikan yang ada sekitar rumpon menggunakan bantuan lampu atau cahaya, melakukan setting dan hauling. Tahapan Pengoperasian alat tangkap purse seine oleh KM. Sumber Abadi sudah sesuai dengan tahapan pengoperasian purse seine yang dinyatakan oleh Adi, Bambang, \& Asriyanto (2014). Adapun tahap-tahap pengoperasian purse seine yang dilakukan oleh KM. Sumber Abadi adalah sebagai berikut:

\section{Penurunan alat tangkap (setting)}

Dalam menentukan titik awal penurunan alat tangkap (setting) ada beberapa hal yang perlu diperhatikan oleh nakhoda kapal KM. Sumber Abadi antaralain adalah sebagai berikut:

\section{A. Arus}

Arah arus perlu diperhatikan karena ketika jaring lingkar telah berada di dalam air maka akan sangat terpengaruh oleh kekuatan arus. Pakmet (2017) menyatakan bahwa posisi yang diharapkan adalah arus mendorong alat tangkap menjahui badan kapal sehingga alat tangkap tidak masuk ke bawah kapal (kapal masuk ke dalam lingkaran jaring) sehingga penaikan alat tangkap tidak terlalu berat atau tidak tersangkut baling-baling. Gambar posisi kapal dan jaring terhadap arus disajikan pada Gambar 9. 


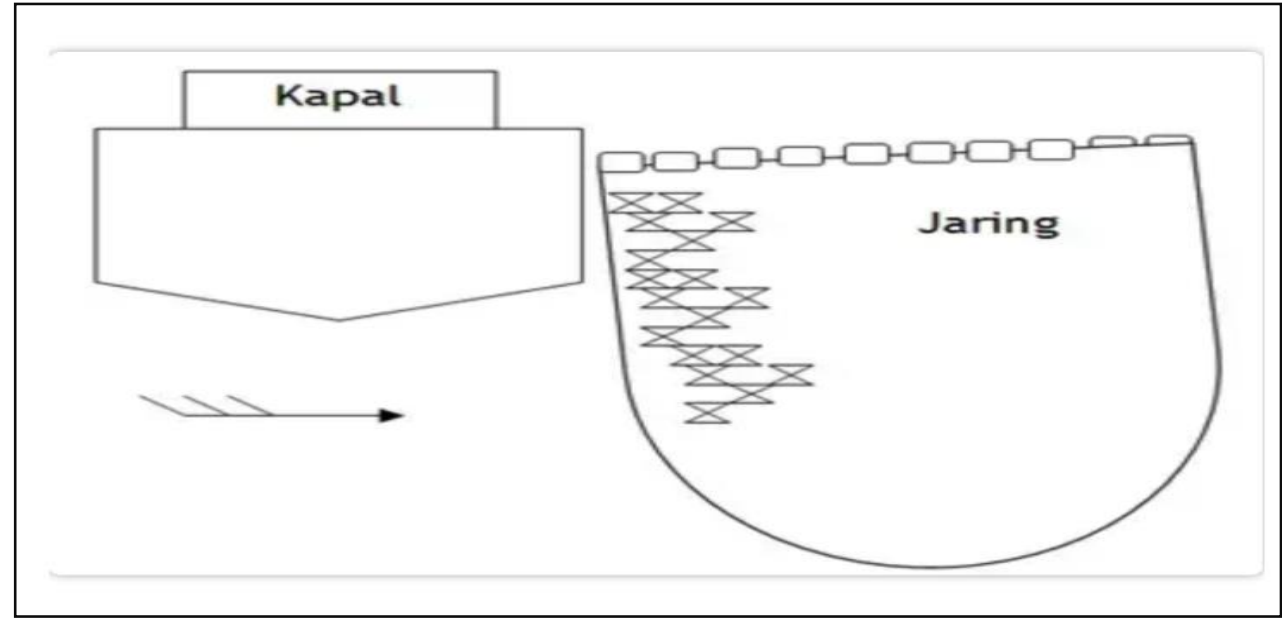

Gambar 9. Posisi Kapal dan Jaring Terhadap Arus.

\section{B. Angin}

Arah arus juga diperlu diperhatikan karena bagian kapal yag berada di atas air akan terpengaruh oleh angin. Posisi yang salah dapat menyebabkan kapal terdorong masuk ke lingkaran jaring karena itu diharapkan jaring berada diantara kapal dan arah datangnya angin sehingga badan kapal terdorong menjahui jaring. Posisi kapal dan jaring terhadap angin disajikan pada Gambar 10.

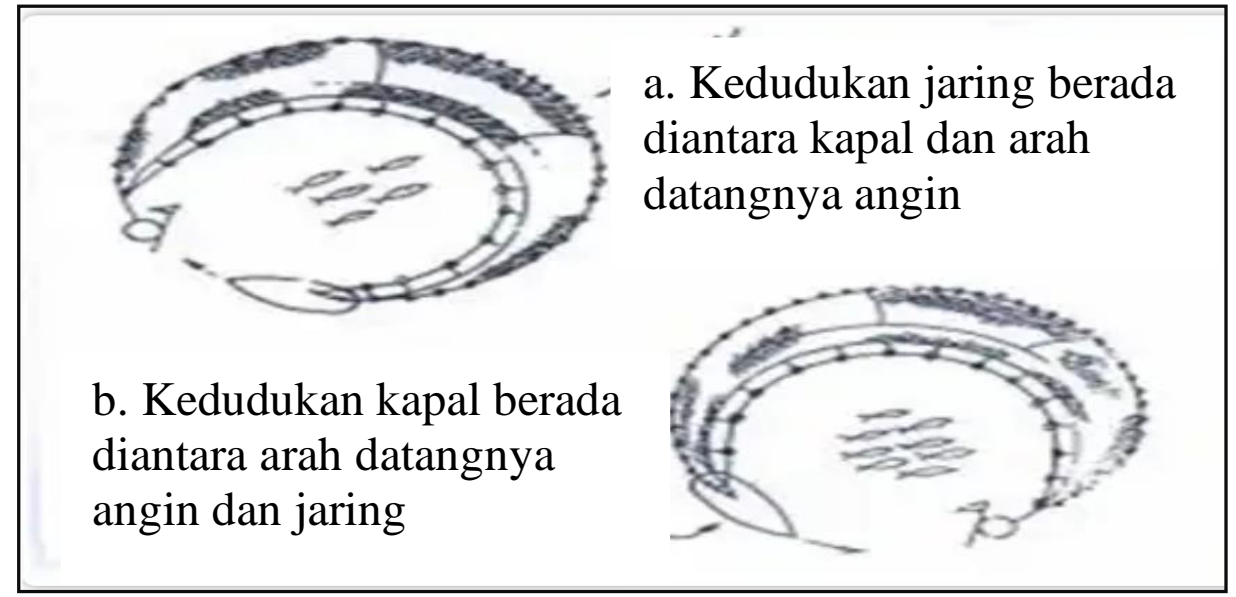

Gambar 10. Posisi Kapal dan Jaring Terhadap Angin.

Setelah memperhatikan hal tersebut nakhoda langsung memberikan tanda berupa mesin utama dinyalakan, bahwa persiapan setting akan dimulai. Kegiatan setting diawali dengan menurunkan palung, palung tersebut diawaki oleh 2 orang ABK dan membawa 6 buah lampu atraktor yang nantinya palung tersebut akan menggantikan lampu robot dari kapal. Kemudian lampu robot yang ada diatas kapal dimatikan satu persatu dimulai dari lampu yang berada dihaluan hingga lampu yang ada diburitan kapal. Setelah semua lampu yang ada diatas kapal mati,palung akan menghanyut mengikuti arus sejauh 40-50 meter, kemudian jangkar akan dinaikan ke atas kapal dan nakhoda segera mengarahkan kapalnya untuk mendekatipalung tersebut dengan jarak 40-50 meter serta mengatur posisi kapal disesuaikan dengan keadaan arus dan angin pada saat itu.

Penurunan jaring dilakukan setelah nakhoda memberikan aba-aba "BUANG" dan tukang pelampung akan membuang lampung tanda sebagai titik awal settingdan disusul dengan tukang batu membuang tali kerut dan pemberat, bersamaan dengan melajunya kapal, bagian-bagian jaring mulai ikut turun kelaut. Kecepatan kapal berkisar antara 6-7 knot tergantung dari kekuatan mesin utama, waktu yang diperlukan dalam setting berkisar 3-5 menit. Agar proses penurunan jaringlancar, untuk 
menghindari kemungkinan terbelit atau tersangkutnya bagian-bagian jaring maka ada petugas yang membantu dan mengawasi proses penurunan jaring tersebut, yaitu:

1. Satu orang mengawasi/membantu penurunan pelampung,

2. Satu orang mengawasi/membantu penurunan pemberat, dan

3. Satu orang mengawasi/membantu penurunan tali kerut.

Gambar Posisi ABK yang bertugas pada saat penurunan jaring (setting) disajikan pada Gambar 11.

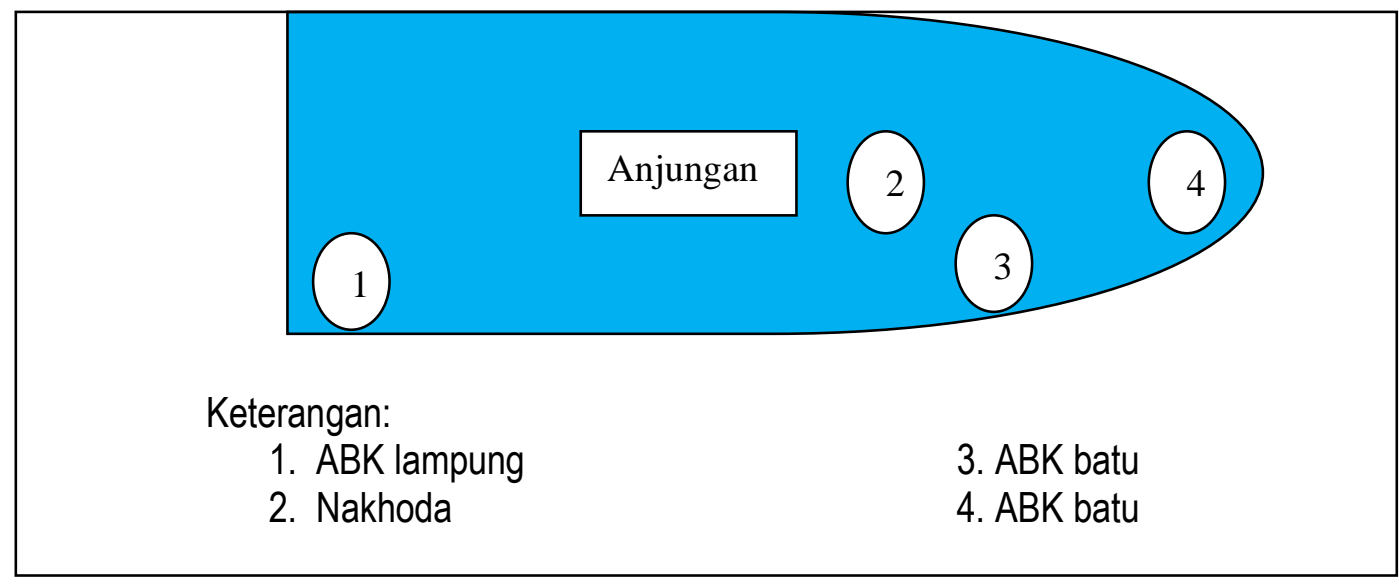

\section{Gambar 11. Posisi ABK Pada Saat Setting.}

Beberapa meter sebelum titik akhir, kecepatan kapal akan dinetralkan hingga kapal melaju dengan sisa tenaga. Ketika kapal ingin mendekati titik awal, maka mesin kapal akan bergerak mundur agar kapal tiba-tiba, hal ini tergantung dari teknik yang biasa dilakukan oleh nakhoda.

\section{Penarikan tali kerut}

Penarikan tali kerut dilakukan sesaat setelah ABK yang ada di haluan kapal mencapai lampu tanda yang dibuang pada saat awal setting. Penarikan lampu tanda keatas kapal dibantu oleh beberapa orang ABK agar penarikannya dapat dilakukan dengan cepat, setelah tali kerut didapatkan selanjutnya tali kerut ditarik dengan menggunakan gardan.

Penarikan tali kerut ini dilakukan dengan cepat sampai semua cincin-cincin dinaikan ke atas kapal dan hal ini lah yang membuat purse seine akan berbentuk mangkuksehingga ikan yang berada di dalam akan terkurung. Tali kerut ditarik sambil disusun kembali ke bagian haluan kapal agar memudahkan untuk kapal melakukan setting selanjutnya. KM. Sumber Abadi memerlukan waktu 40 sampai 50 menit untuk penarikan tali kerut, sesuai Syahputra (2020) menyatakan bahwa rata-rata waktu penarikan penarikan tali kerut adalah 2.480 detik atau 41 menit.

\section{Penarikan badan jaring(hauling)}

Setelah semua cincin dinaikan ke atas kapal, lampu robot diatas kapal akan kembali dihidupkan semua, agar memudahkan ABK dalam melakukan pekerjaannya. Kemudian badan jaring akan ditarik oleh ABK keatas kapal dengan menggunakan mesin bantu robot (power block). Bagian badan jaring akan ditarik sedikit demi sedikit ke atas kapal sambil disusun dengan rapi agar pada saat dioperasikan kembali badan jaring tidak terbelit dan kusut yang akhirnya dapat menyebabkan sobek.

Badan jaring ditarik hingga hanya bagian kantung saja yang masih berada didalam air.Pengoperasian oleh KM. Sumber Abadi memerlukan waktu 2 sampai 3 jam untuk satu kali pengoperasian, hal itu disebabkan karena dibantu oleh mesin bantu penangkapan yaitu power block. Penarikan jaring dilakukan oleh ABK secara beramai-ramai yang berdiri disisi sebelah kanan lambung kapal untuk melakukan penarikan jaring. Hal ini sesuai dengan yang dinyatakan oleh Hutapea, Mardiah, Arkham, Sari,\& Syaputra (2020). 


\section{Penaikan Hasil Tangkapan (brailing)}

Brailing yaitu tahap terakhir dalam proses penangkapan dimana hasil tangkapan akan diangkat menggunakan serok/tangguk besar. Serok yang digunakan KM. Sumber Abadi berfungsi sebagai menaikkan hasil tangkapan ke atas kapal dalam jumlah yang besar. Muatan serok ketika terisi penuh oleh ikan adalah $1000 \mathrm{~kg}$. Waktu yang dibutuhkan untuk penaikan hasil tangkapan ini tergantung dari jumlah banyak dan sedikitnya ikan, jika hasil tangkapan yang tertangkap banyak maka semakin lama pula waktu yang dibutuhkan. KM. Sumber Abadi memerlukan waktu 5 sampai 30 menit untuk penaikan hasil tangkapan. Gambar penaikan hasil tangkapan disajikan pada Gambar 12.

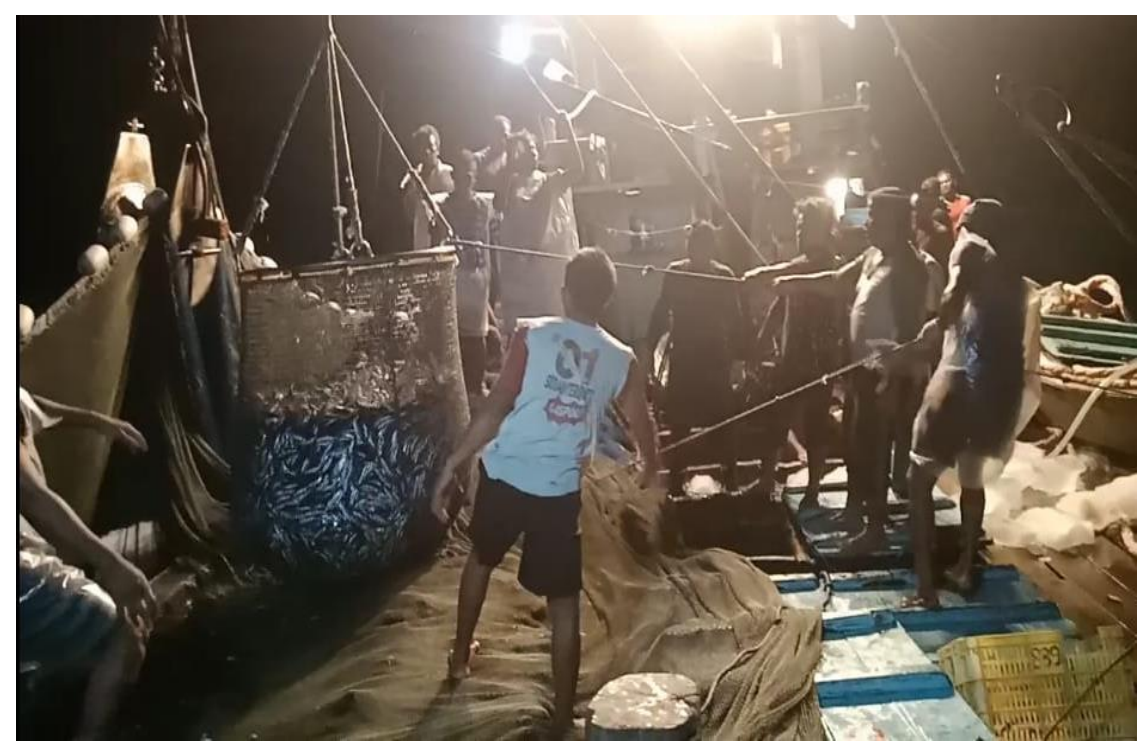

Gambar 12. Penaikan Hasil Tangkapan KM. Sumber Abadi.

\section{Kesimpulan}

Kesimpulan dari penelitian ini menyebutkan bahwa alat bantu penangkapan purse seine dan alat navigasi yang ada di atas KM. Sumber Abadi adalah lampu robot, garden, power block, GPS, echosounder dan radio SSB. Fishing ground KM. Sumber Abadi di WPP 571 Selat Malaka Pengoperasian alat tangkap purse seine oleh KM. Sumber Abadi dilakukan secara bertahap, yaitu penurunan alat tangkap (setting) penarikan tali kerut penarikan badan jaring (Hauling) penaikan hasil tangkapan (brailing), dalam satu kali pengoperasian memakan waktu sebanyak 2-3 jam.

\section{DAFTAR PUSTAKA}

Adi, N., Bambang, A.W., Asriyanto. (2014). Analisis Finasial Usaha Perikanan Tangkap Mini Purse Seine di Pelabuhan Perikanan Pantai (PPP) Tasik Agung Kabupaten Rembang. Journal of Fisheries Resources Utilization Management and Technology, 3(4), 56-65.

Baihaqi \& Hufiadi. (2015). Karakteristik dan Efisiensi Pukat lkan yang Berbasis

Buwono, A., Manullang, S., \& Eneste, M. A. (2020). Perhitungan Kebutuhan Energi Listrik untuk Penerangan pada Kapal Ikan 30 GT dan 10 GT yang Beroperasi di Pantai Pulau Jawa. Universitas Darma Persada, 10(3), 32-39.

Damanik, M. R. S., Lubis, M. R. K \& Astuti, A. J. D. (2016). Kajian Pendekatan Ekosistem dalamPengelolaan Perikanan di Wilayah Pengelolaan Perikanan (WPP) 571 Selat Malaka Provinsi Sumatera Utara. Universitas Negeri Medan, 8(2), 165-176.

di PPS Belawan. Medan.

Hariati, T., Taufik, M., \& Zamroni, A. (2003). Beberapa Aspek Reproduksi Ikan Layang (Decapterus russelli) dan Ikan Banyar (Rastrelliger kanaguna) diPerairan Selat Malaka Indonesia. JPPI Edisi Sumber Daya dan Penangkapan, 11(2),47-56. 
Hutapea. R. Y. F., Mardiah. R. S., Arkham. M. N., Sari. R. P \& Syaputra. W. N. (2020). Studi Pengoperasian dan Konstruksi Purse Seine di KM. Marwah Lampulo Aceh Utara. Coastal and Ocean Journal, 4(1), 47-56.

Kefi, O. S., Katiandagho, E. M., \& Paransa, I. J. (2013).Sukses Pengoperasian Pukat Cincin Sinar Lestari 04 dengan Alat Bantu Rumpon yang Beroperasi di Perairan Lolak Provinsi Sulawesi Utara.Jurnal IImu dan Teknologi Perikanan Tangkap, 1(3),69-75.

Linarwati, M. Fathoni, A., \& Minarsih, M. M. (2016). Studi Deskriptif Pelatihan dan Pengembangan Sumberdaya Manusia Serta Penggunan Metode Behavioral Event Interview dalam Merekrut Karyawan Baru di Bank Mega Cabang Kudus. Fakultas Ekonomi dan Bisnis Universitas Pandanaran Semarang, 2(2), 1-8.

Pratama, M. A. D., Hapsari, T. D., \& Triarso, I. (2016). Faktor-Faktor yang Mempengaruhi Hasil Produksi Unit Penangkapan Purse seine (Gardan) di Fishing Base PPP Muncar, Banyuwangi, Jawa Timur Saintek Perikanan,11(2), 120-128.

Silitonga.C., Isnaiah \& Syofyan. I. (2016). Studi Konstruksi Alat Tangkap Pukat Cincin (Purse Seine) di Pelabuhan Perikanan Nusantara (PPN) Sibolga Kelurahan Pondok Batu Kota Sibolga Provinsi Sumatera Utara.Sibolga. Indonesia.

Steven, Tel. (2017). Komposisi Hasil Tangkapan dan Daerah Penangkapan olehKapal Purse Seine Berdasarkan Vessel Monitoring Sistem (VMS) Di WPP 571 Selat Malaka.Indralya. Universitas Sriwijaya.

Suman, A., Satria, F., Nugraha, B., Priatna, A., Amri, K \& Mahiswara. (2018). Status Stok Sumber Daya Ikan Tahun 2016 di Wilayah Pengelolaan Perikanan Negara Republik Indonesia (WPP NRI) dan Alternatif Pengelolaannya. Jurnal Kebijakan Perikanan Indonesia,10(2), 107-128.

Surur, F. (2010). Purse Seine.STP Press Jakarta.Kendiri.301 hal.

Syahputra, W. N. (2020). Keterkaitan Pengerutan Tali Kerut Purse Seine Terhadap Hasil Tangkapan di KM. Marwah dan KM. Baro Jaya di PPS Kutaraja Aceh Utara.Dumai. Indonesia. 
